1 Dr. Fahmuda Akhter MBBS, FCPS (Paed) Registrar, Dept of Paediatrics Northern International Medical College, Dhaka

2 Dr. B H Nazma Yasmeen Associate professor and Head Dept of Paediatrics Northern International Medical College, Dhaka

3 Prof. Mohammad Hanif Professor and Head Dept of Paediatric Nephrology Dhaka Shishu Hospital, Dhaka

${ }^{4}$ Dr. Shushoma Roy Child Specialist Square Hospital, Dhaka

\section{Correspondence}

Dr. Fahmuda Akhter MBBS, FCPS (Paed ), Registrar Dept of Paediatrics Northern International Medical College, Dhaka

\title{
Renal Functional Reserve by Measuring the Creatinine Clearance in Children : Previously Diagnosed and Improved after Acute Renal Failure
}

\author{
F Akhter ${ }^{1}$, B H N Yasmeen ${ }^{2}$, M Hanif ${ }^{3}$, S Roy ${ }^{4}$
}

\section{Abstract}

Background : Acute Renal Failure (ARF) is a life threatening condition causing significant morbidity and mortality in children. Many studies on adult ARF survivors showed that renal insufficiency persisted after an attack of ARF. Children may be more susceptible to this injury due to immaturity and ongoing growth of the kidney.

Objective : This study was conducted to assess the renal functional reserve or detect any sign of renal injury in children after an episode of Acute Renal Failure

Methods : This prospective study was carried out in the Renal and Dialysis unit, Dhaka Shishu Hospital in 2007, January . Thirty patients were enrolled in this study by searching data held in the study centre.

Results : Thirty (30) patients were selected in this study. Among them $46.7 \%$ was in the group $>5-10$ years, only $10.0 \%$ was in age group $<1$ year and more than 10 years respectively. Male were $63.3 \%$, female were $36.7 \%$.Causes of acute renal failure were diarrhoea with dehydration $43.3 \%$, septicaemia $20.0 \%$, Haemolytic Uraemic Syndrome (HUS) 20\%, Acute Glomerulo Nephrities (AGN) 10.0\%, Henoch Schonlein Purpura ( HSP) 3.3\% and hepato renal syndrome 3.3\%. During follow up Glomerular Filtration Rate(GFR) of the patients were in stage 1 in $76.7 \%$ cases, $10.0 \%$ in stage 2, 6.7\% in stage 3 stage and in stage $4 \& 53.3 \%$ cases.23.3\% patients were found with GFR between stage 2 to stage 5 , who had ARF due to HUS and HSP. The incidence of hypertension and proteinuria was found in $13.3 \%$ cases of HUS.

Conclusion : The progressive nature of acute renal failure which may cause chronic kidney disease is an important observation.

\section{Introduction}

Acute Renal Failure is defined as sudden loss of the ability of the kidneys to excrete excess water, regulate electrolytes and acid base status and eliminate waste products from the body. It occurs in 2-3\% of children admitted in all paediatric tertiary hospitals and as many as $8 \%$ of infants in the neonatal intensive care units. $^{1}$ Recent studies in developed countries have shown, that ARF in children now a days result from complications of systemic disease such as multi-organ failure. ${ }^{2}$ In the developing countries ARF still results from gastroenteritis and glomerulonephritis. ${ }^{3}$ A study in Bangladesh has shown that acute Tubular Necrosis, Haemolytic Uraemic Syndrome and septicemia are also the common causes of $\mathrm{ARF}^{4}$ Optimal medical management and dialysis can reverse the derangements caused by ARF. Despite all these, mortality of ARF is still very high. In developed countries, recent studies report in hospital death rates of about $30-46 \% .^{5}$ In the developing countries mortality rates approaches to $40-60 \%^{3}$. Only a few studies report on long-term outcome and degree of residual renal impairment in the surviving patients and these studies are limited to few renal conditions. Many studies on adult ARF survivors showed that renal insufficiency persisted after an attack of ARF. The paediatric population, likewise, has not been studied so extensively.

Children may be more susceptible to this injury. Therefore follow up of a child who had an episode of Acute Renal Failure is needed to detect any deterioration of renal functional reserve which will alert the clinicians to design appropriate monitoring programs for such children.

\section{Methodology}

This prospective study was carried out over one year in the Renal and Dialysis unit, Dhaka Shishu Hospital in 2007, January. Thirty patients admitted with ARF and discharged after recovery, were enrolled in this study by searching data held in the study centre. Patients with Chronic kidney disease or with evidence of any congenital structural renal disease or obstructive uropathy were excluded. Parents singed a formal consent after explaining the benefit and purpose of the study. Patient's data such as age, sex, medical history and findings of physical examinations, laboratory data on admission and discharge were collected from their files. During follow up after 4 month of discharge the blood pressure (BP) was measured. Hypertension in a child was considered when $\mathrm{BP}$ value is $>95^{\text {th }}$ percentile corresponding to age and sex. Investigations such as: S.Creatinine, Creatinine clearance $(\mathrm{CrCl})$ and Urine $R / M / E$ to evaluate the renal injury or renal functional reserve were done. Creatinine clearance $(\mathrm{CrCl})$ is a convenient method for GFR assessment. Timed urine collection (24hour) is required. A blood sample for measuring the $\mathrm{S}$. Creatinine around the mid collection period is needed. $^{2}$

$$
\begin{aligned}
\mathrm{Crcl}= & \mathrm{UxV} \\
& \mathrm{P} \times \mathrm{T} \times 1.73 \mathrm{~m}^{2} \\
= & \mathrm{ml} / \mathrm{min} / 1.73 \mathrm{~m}^{2}
\end{aligned}
$$


$(\mathrm{U}=$ urine creatinine $(\mathrm{mg} / \mathrm{dl})$

$\mathrm{V}=24$ hour urine volume $(\mathrm{ml})$

$\mathrm{P}=\mathrm{S}$. creatinine $(\mathrm{mg} / \mathrm{dl})$

$\mathrm{T}=1440$ (number of minutes in 24 hours)

\section{Statistical analysis}

Result was expressed as mean \pm standard deviation (SD) and frequency distribution. Percentages were calculated to find out the proportion of the findings. Further statistical analysis was done by computer software devised as the statistical packages for social scientist (SPSS). The results were presented in Tables, Figures, and Diagrams etc. For statistical significance difference and correlation test was done. A probability ' $p$ ' value $<0.05(p<0.05$ ) was considered as significant.

\section{Results}

A total of 30 patients were selected in this study. Out of which 19 were male, 11 were female and the age range was 1 month to 12 years. It was found that among the patients, highest percentage $(46.7 \%)$ was in the group $>5-10$ years,33.3\% in 1 to 5 years and only $10.0 \%$ was in age group $<1$ years and more than 10 years respectively (Fig. 1)

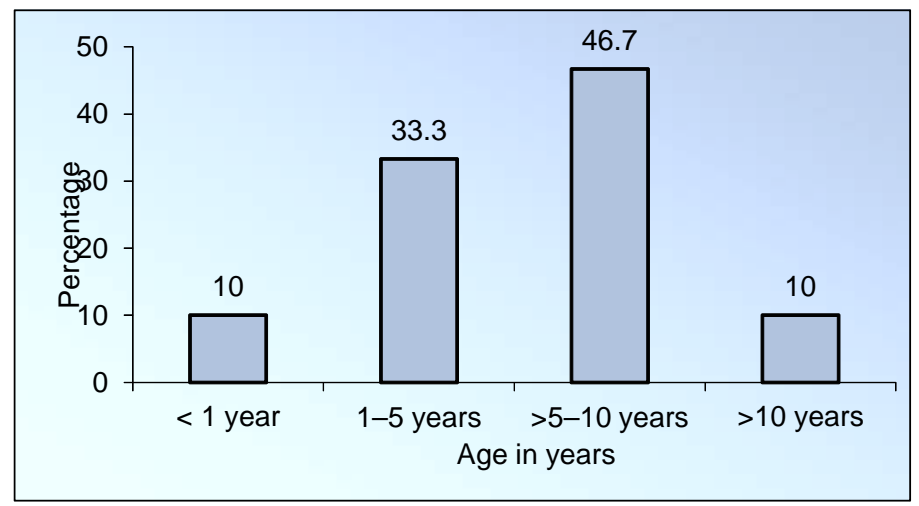

Fig 1: Age distribution of the patients

The male patients were $63.3 \%$, female were $36.7 \%$ were female. Female male ratio was 1:1.7 (Fig 2).

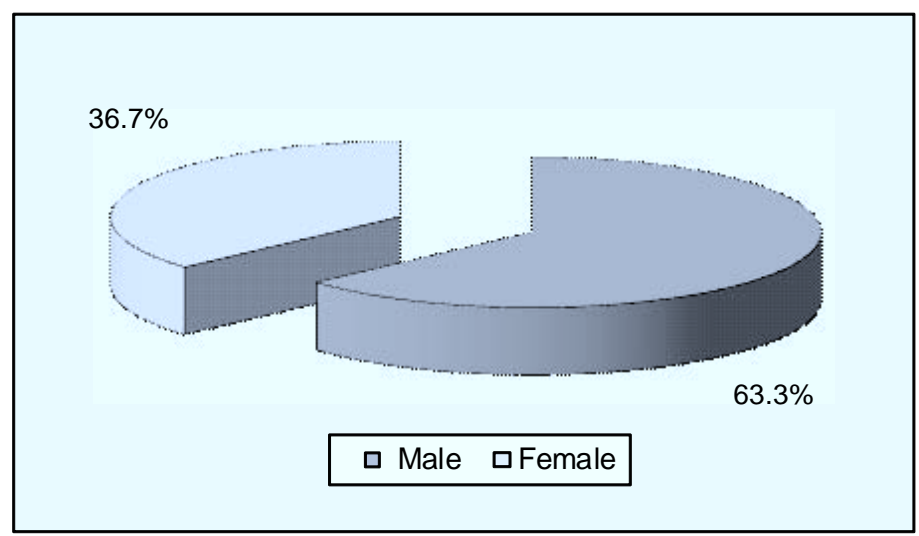

Fig 2: Sex distribution of the patients

Causes of acute renal failure were diarrhoea with dehydration $43.3 \%$ septicaemia $20.0 \%$, HUS $20 \%$, AGN $10.0 \%$, HSP 3.3\% \& hepato renal syndrome $3.3 \%$ (Fig 3)

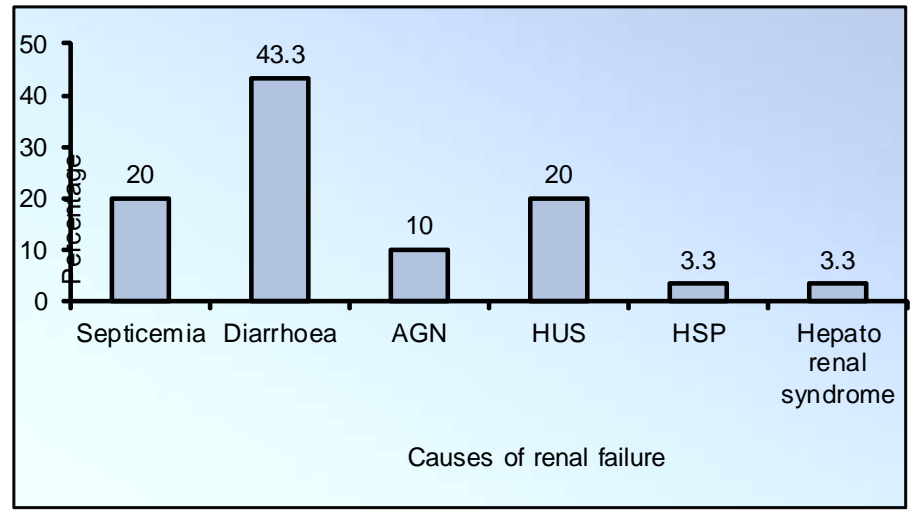

Fig 3: Causes of renal failure of the patients

The mean serum Creatinine was $233.3 \pm 127.2 \mathrm{mmol} / \mathrm{L}$ ranging from 120 to $550 \mathrm{ml} / \mathrm{min}$ of the study subject during admission in the hospital (Table 1)

Table 1: Serum Creatinine of the study patients during admission with ARF Serum Creatinine $\mathrm{mmo} / \mathrm{L}$

$>110$ - $<200$

$\begin{array}{cc}\text { No. } & \% \\ 4 & 13.3 \\ 6 & 20.0 \\ 12 & 40.0 \\ 8 & 26.7\end{array}$

$>300-<500$

$>500$

$233.3 \pm 127.2$

Mean \pm SD

120,550

Range (min, max)

26.7

Most of the patients were found in stage $1(76.7 \%)$ followed by stage 2 (10.0\%), stage $3(6.7 \%)$ and stage $4 \& 5$ was (3.3\%). 7 patients ( 6 HUS \& 1 HSP) whose GFR was found between stage 2 to stage 5 had ARF due to HUS and HSP (Table 2)

\section{Table 2: Status of GFR of the study patients during follow up} Stage

$1\left(90 \mathrm{ml} / \mathrm{min} / 1.73 \mathrm{~m}^{2}\right)$ No. $\%$

$2\left(60-89 \mathrm{ml} / \mathrm{min} / 1.73 \mathrm{~m}^{2}\right)$

23 76.7

$3\left(30-59 \mathrm{ml} / \mathrm{min} / 1.73 \mathrm{~m}^{2}\right)$

3

10.0

4 (15 - $\left.29 \mathrm{ml} / \mathrm{min} / 1.73 \mathrm{~m}^{2}\right)$

2

6.7

$5\left(<15 \mathrm{ml} / \mathrm{min} / 1.73 \mathrm{~m}^{2}\right)$

1

Total

1

30

100.0

HUS $(20.0 \%)$ and $\operatorname{HSP}(3.3 \%)$ are found as the cause of reduced GFR in the study patients (Table 3).

\section{Table 3: Cause of reduced GFR of the study patients}

$\begin{array}{lcc} & \text { No. } & \% \\ \text { HUS } & 6 & 20.0 \\ \text { HSP } & 1 & 3.3 \\ \text { Total } & 7 & 20.3\end{array}$

The incidence of hypertension and proteinuria was found in 13.3\% cases of HUS 
Table 4: Incidence of hypertension and proteinuria found in the HUS patients No. $\%$

Hypertension and proteinuria

4

\section{3}

No hypertension and proteinuria

2

13.3

6.7

Total HUS Patients

6

\section{Correlation seen between serum creatinine and GFR:}

Serum Creatinines of 30 cases during follow up are expressed in $\mathrm{mmol} / \mathrm{l}$ and their GFR expressed in $\mathrm{ml} / \mathrm{min} / 1.73 \mathrm{~m}^{2}$. A significant negative correlation was found between Serum Creatinine and GFR $\left(\mathrm{ml} / \mathrm{min} / 1.73 \mathrm{~m}^{2}\right)$

The value of Pearson's correlation coefficient was -0.880 and it is significant $(p<0.001)$. Therefore, there was a linear negative association between Serum Creatinine and GFR $\left(\mathrm{ml} / \mathrm{min} / 1.73 \mathrm{~m}^{2}\right)$ in the study population.

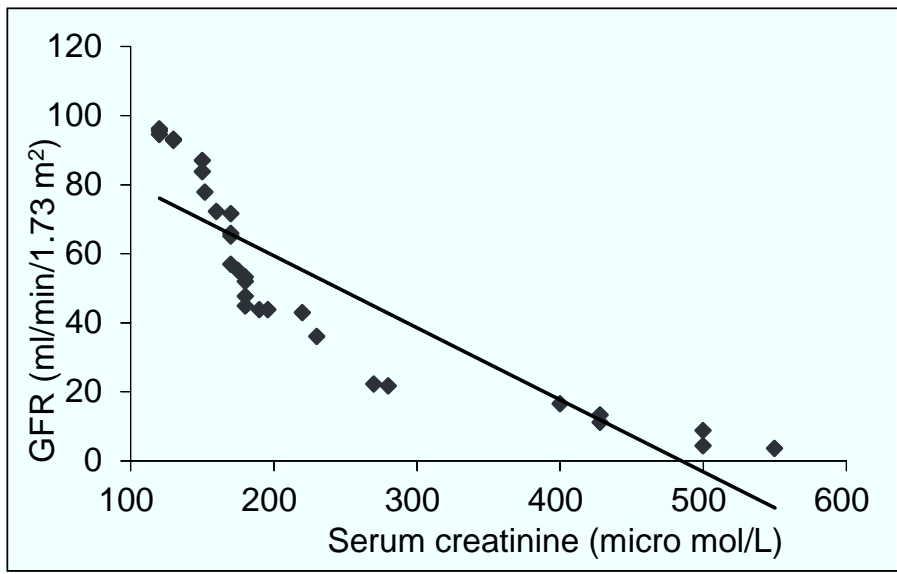

Fig 4: The scatter diagram shows significant relationship ( $r=-0.880)$ between serum creatinine $(\mathrm{mmol} / \mathrm{I})$ and GFR $\mathrm{ml} / \mathrm{min} / 1.73 \mathrm{~m}^{2}$ )

\section{Discussion}

ARF is a serious complication of many diseases and may follow a number of medical or surgical therapies. The cause of ARF in children has changed substantially over recent decades. In developed countries, data showed that paediatric ARF has changed from primary renal disease to renal involvement secondary to other systemic illness. The most common causes of ARF in hospitalized children are renal ischemia (21\%), nephrotoxic medications (16\%) and sepsis (11\%). Primary renal disease accounted for only $7 \%$ cases. $^{3}$ In the developing countries ARF results mainly from infectious diseases including dehydration following gastroenteritis ${ }^{3,6}$. A striking observation of this study was that $43.3 \%$ had acute renal failure due to diarrhoea with dehydration, $20 \%$ due to septicaemia, and $20 \%$ due to HUS, $10 \%$ due to AGN, 3.3\% due to HSP and $3.3 \%$ due to hepato renal syndrome.

A study conducted in Children and Young People's Kidney Unit, Nottingham city hospital, UK to see the outcome of children after ARF showed that $49 \%$ maintained their normal renal function after an episode of ARF, $20 \%$ died, $8 \%$ developed CRF, $7 \%$ children had developed hypertension and proteinuria. ${ }^{7}$ In one of the first large series published on long term outcome of HUS, it was showed that of 124 patients almost half had persistent signs of renal disease and $18 \%$ progressed to ESRD ${ }^{8}$. O'Reagan et al reported that $30 \%$ of 37 children with HUS had significant impairment of GFR ${ }^{9}$. Another study showed that after 5 years 23\% children surviving HUS developed renal sequels

such as proteinuria, hypertension and had reduced glomeruler filtration rate. ${ }^{10}$ Patients with chronic renal insufficiency show a linear fall of creatinine clearance with time. ${ }^{11}$ In this study we found that $23.3 \%$ patients who had reduced GFR: $10 \%$ had mild reduction of GFR, $6.7 \%$ moderate reduction, 3.3\% severe and 3.3\% progressed to ESRD. Patients who had decreased GFR, 20\% were due to HUS and 3.3\% was due to HSP. $13 \%$ cases of HUS also have renal sequels such as hypertension and proteinuria. This study also showed that these $26.7 \%$ patient all had S. Creatinine $>500 \mathrm{~mol} / \mathrm{l}$ during their admission for which they had undergone peritoneal dialysis. A correlation between $\mathrm{S}$. Creatinine and decreased GFR is seen in this study. The higher the level of $\mathrm{S}$. Creatinine was during admission the incidence of decreased GFR is more.

\section{Conclusion}

Several studies on paediatric patients after ARF clearly illustrated that ARF in the paediatric patient is a significant risk factor for later morbidity and mortality. Therefore additional studies with children who suffered an episode of ARF due to any renal cause are needed to detect future risk for renal disease. Such children should under go regular follow up and measurement of creatinine clearance within the first few years at least annually for several years after the initial insult.

\section{References}

1. Beth A, Vogt \&Ellis D, Avner: Renal Failure.R.E. Behrman, R.M. Kligeman, H.B Jenson (editors): Nelson's Textbook of Paediatrics $17^{\text {th }}$ edition:

2. Otukesh $\mathrm{H}$, Hoseini R, Hooman $\mathrm{N}$, Chalian $\mathrm{M}$, Chalian $\mathrm{H}$, Tabarroki A.Prognosis of acute renal failure in children. Pediatr Nephrol 2006; Sept 8:25-26

3. Shah BV, Almeida AF, Chawla KP et al. Acute renal failure in pediatric population in the tropics Postgrad Med 1985; 31:134-139

4. M Hanif, L P Roy. Acute Renal Failure: Outcome of 38 patients who required peritoneal dialysis. Bangladesh J Child Health 1989; 13:95-101

5. Bunchman TE, McBryde KD, Mottes TE et al. Pediatric acute renal failure: outcome by modality and disease. Pediatr Nephrol 2001; 16:1067-1071

6. Nash K, Hafeez A, Hou S. Hospital acquired renal insufficiency. Am J Kidney Dis 2002; 39:930-936

7. Smith, L.H. Jr. et al. 1955. . Post-traumatic renal insufficiency in military casualties II. Management, use of an artificial kidney, prognosis. Am. J. Med. 18:187-198

8. SieglerRL, Milligan MK, Burningham th, Christoferson R, Longterm Outcome and prognostic indicators in the HUS.J Paediatr.1991; 118:195-200

9. O'Reagon S, blais N,Russo P,Pison CF, RanssamEHUS: GFR 6 to 11 years later. Clin Nephrol 32:217-220

10. Bywaters, E.G., and Beall, D. 1941.Crush injuries with impairment of renal function. Br Med. J. 1:427-43.

11. Bagga A, Srivastava RN. In Diagnostic Evaluation Srivastava RN, Bagg A, editors. Paediatric Nephrology. 5th edition. New Delhi India : J aypee brother 2011. : 37. 